\title{
Magnitude of social determinants in high risk areas of leprosy in a hyperendemic city of northeastern Brazil: An ecological study
}

\author{
ANTÔNIO CARLOS VIEIRA RAMOS ${ }^{\mathrm{a}}$, \\ MARCELINO SANTOS NETO ${ }^{b}$, \\ LUIZ HENRIQUE ARROYO ${ }^{\mathrm{a}}$, MELLINA YAMAMURA ${ }^{\mathrm{c}}$, \\ IVANELIZA SIMIONATO ASSIS ${ }^{\mathrm{d}}$, \\ JOSILENEDÁLIA ALVES ${ }^{\mathrm{e}}$, \\ MARCOS AUGUSTO MORAES ARCOVERDE, \\ LUANASELES ALVES ${ }^{\mathrm{a}}$, THAÍSZAMBONI BERRA ${ }^{\mathrm{a}}$, \\ JOSÉFRANCISCO MARTORELIJÚNIOR ${ }^{\mathrm{a}}$, \\ FLÁVIA MENEGUETTI PIER I ${ }^{\mathrm{g}}$ \& \\ RICARDO ALEXANDRE ARCÊNCIO ${ }^{\mathrm{a}}$ \\ ${ }^{a}$ Department of Maternal-Infant Nursing and Public Health, University of \\ São Paulo at Ribeirão Preto College of Nursing, Ribeirão Preto, São Paulo, \\ Brazil \\ ${ }^{\mathrm{b}}$ Center for Social Sciences, Health and Technology, Federal University of \\ Maranhão, Imperatriz, Maranhão, Brazil \\ ${ }^{\mathrm{c}}$ Department of Nursing, Federal University of São Carlos, São Carlos, São \\ Paulo, Brazil \\ ${ }^{\mathrm{d}}$ University Center Dinâmica of Cataratas, Foz do Iguaçu, Paraná, Brazil \\ ${ }^{\mathrm{e}}$ Institute of Biological Sciences and Health, Federal University of Mato \\ Grosso, Campus Barra do Garças, Barra do Garças, Mato Grosso, Brazil \\ ${ }^{\mathrm{f}}$ Center for Education, Letters and Health, Western Paraná State University, \\ Campus Foz do Iguaçu, Foz do Iguaçu, Paraná, Brazil \\ ${ }^{\mathrm{g}}$ Department of Nursing, Londrina State University, Londrina, Paraná, \\ Brazil
}

Accepted for publication 29 October 2019

\begin{abstract}
Summary
Objective: To investigate the association of certain social determinants with areas at high-risk for leprosy in a hyperendemic city in northeastern Brazil.

Methods: An ecological study was carried out in Imperatriz, a hyperendemic municipality of northeastern Brazil. The units of analysis were urban census tracts, in which variables related to the number of dwellers per domicile, literacy and per capita monthly income were selected for the construction of the social determinants
\end{abstract}

\footnotetext{
Correspondence to: Antônio Carlos Vieira Ramos, Department of Maternal-Infant Nursing and Public Health, University of São Paulo at Ribeirão Preto College of Nursing, Avenida dos Bandeirantes, 3900 - Monte Alegre, Ribeirão Preto - SP, 14040-902, Brazil (e-mail: antonio.vieiraramos@outlook.com)
} 
dimensions, by means of the Principal Components Analysis (PCA) technique. Spatial scan statistics were applied to identify areas of elevated leprosy risk and binary logistic regression was performed, considering the high-risk areas as the dependent variable and the social determinants dimensions as the independent variable. The Odds Ratios (ORs) were calculated with its 95\% Confidence Intervals (CIs). The Receiver Operating Characteristic (ROC) Curve was applied to verify the discriminative power of the model. Type I error was set at $5 \%(p<0.05)$.

Results: 2,552 leprosy cases were georeferenced and the scan statistic identified highrisk areas. The logistic model showed that social determinants were associated with high-risk areas $(\mathrm{OR}=1.25,95 \% \mathrm{CI}=1.07-1.49, p=0.006)$. The area under the ROC curve value confirmed the discriminatory capacity for the model at $65 \%$, which was considered sufficient.

Conclusions: The high-risk areas for leprosy are associated with social determinants of low household per capita income, low educational levels and high numbers of residents per household.

Keywords: Leprosy, spatial analysis, social determinants

\section{Introduction}

Leprosy is a chronic infectious disease caused by Mycobacterium leprae, which predominantly affects the skin and the peripheral nervous system, resulting in neuropathies and long-term associated consequences, including deformities and physical disabilities. ${ }^{1}$

Despite the elimination of the disease in some countries of the world (prevalence $<1$ case per 10,000 inhabitants) leprosy persists in developing countries as a public health issue, as part of the Neglected Tropical Diseases group. ${ }^{2-4}$

The World Health Organization (WHO) published the Global Leprosy Strategy 2016-2020: Accelerating towards a leprosy-free world, ${ }^{5}$ the goals of which are to reduce the global and local burden of leprosy, with the reduction of cases of children with deformities, reduction of new cases diagnosed with Grade 2 disability to less than one case per 1 million inhabitants and revision of all laws that lead to discrimination of patients with leprosy. ${ }^{5}$

While a global detection rate of 2.77 cases per 100,000 inhabitants was estimated in 2017, the countries with the highest number of cases are India, Brazil and Indonesia, with $80.2 \%$ of reported cases. ${ }^{6}$ Brazil presented a rate of detection of new cases of 12.94 cases per 100,000 inhabitants, in which it was responsible for $92.3 \%$ of the cases reported in the Americas, 6,7 also showing a Grade 2 disability rate of 8.30 cases per 1 million inhabitants, and detection in children under 15 of 3.72 cases per 100,000 children. Some Brazilian states have already achieved the goal of eliminating leprosy; however, the northern, central-western and northeast regions of the country still have high rates of leprosy.

A spatial analysis study carried out in 2009 in Brazil identified that the states of Mato Grosso, Tocantins, Rondônia, Pará and Maranhão comprise high-risk areas for the persistent transmission of the disease. ${ }^{8}$ Maranhão, defined as hyperendemic for leprosy, had a detection rate of 44.34 new cases per 100,000 inhabitants in 2017, well above the global and Brazilian means. ${ }^{9}$

Considering that the treatment for leprosy is available and free of charge worldwide, it is assumed that the main barrier to elimination of the disease is related to the social determinants, such as situations of poverty, unhealthy environments and difficulties of leprosy patients in accessing to the health care services. 
Spatial analysis studies conducted in Indonesia, ${ }^{10,11}$ India, ${ }^{12}$ Nigeria, ${ }^{13,14}$ Bangladesh $^{15}$ and Brazil $^{16-25}$ present evidence that leprosy presents focal behavior, with the formation of clusters, and that the disease has an association with social determinants, such as precarious housing conditions, high numbers of residents per household, low levels of education, rural exodus and difficulties in access and accessibility to health services.

Among the studies reporting association of the disease with social determinants, the authors did not identify any that studied the association of high-risk areas of leprosy with social determinants, as well as developing a predictive model of this association. Such predictive studies may be helpful in the planning actions in health and in prioritizing areas for promoting equity of access and elimination of the disease. Therefore, the study aimed to investigate the association of certain social determinants with areas at high-risk for leprosy in a hyperendemic city in northeastern Brazil.

\section{Methods}

\section{STUDY DESIGN AND RESEARCH SCENARIO}

This was an ecological study, ${ }^{26}$ conducted in the city of Imperatriz, Maranhão state, which is located in the northeastern region of Brazil (Figure 1), $626 \mathrm{~km}$ from the state capital, São Luís, being the second largest population, economic, political and cultural center of Maranhão. Imperatriz has a population of 247,505 inhabitants, with a population density of 180.79 inhabitants $/ \mathrm{km}^{2}$ and a territorial area of $1,368,988 \mathrm{~km}^{2} .{ }^{27}$ Regarding the Health Care Network, it has 102 health facilities registered in the Brazilian Nation Health System (Sistema Único de Saúde - SUS) and is divided into four health districts: 1. Vila Nova, 2. Vila Lobão, 3. Bacuri and 4. Santa Rita, with each district being composed of a variable number of neighborhoods, according to their populations. ${ }^{28}$ Concerning socioeconomic indicators, the city has an illiteracy rate of $9.7 \%$, life expectancy at birth of 73.2 years, Human Development Index (HDI) of 0.73 , social exclusion index of 0.6 , incidence of poverty of $55.28 \%$ and Gini Index of 0.46 . Considering basic sanitation, $23 \%$ of the city has a sewage network and $86 \%$ a supply of drinking water. ${ }^{27,28}$ From 2006 to 2016, the rate of detection of new cases of leprosy in the state of Maranhão was 59.03 cases per 100,000 inhabitants, with it being the third most endemic disease in Brazil. ${ }^{7}$ In Imperatriz, in the same period, the detection rate was 109.03 cases per 100,000 inhabitants, which places it in a situation of hyperendemicity. ${ }^{7}$

\section{STUDY POPULATION AND INFORMATION SOURCES}

All cases of leprosy (ICD 10 - A30.0 to A30.8) reported in the Notifiable Disease Information System (SINAN) between 2006 and 2016 were considered. The SINAN is the Brazilian information system responsible for registering and processing information on notifiable diseases throughout Brazil, providing information, bulletins and reports on morbidity, making it an important Brazilian epidemiological database. ${ }^{29}$ The selected variables were: date of notification, date of diagnosis, date of birth, sex, education, operational classification (Paucibacillary and Multibacillary leprosy), clinical form, assessment of the degree of physical disability at diagnosis, and residence address. Data were collected from the Health Surveillance Service of the Imperatriz Regional Health Management Unit, of the state government of Maranhão in May 2018. In the collection process, the information was tabulated in spreadsheets using the Microsoft Excel $^{\circledR} 2013$ software, performing the process of validating the database and removing duplicate notifications. 


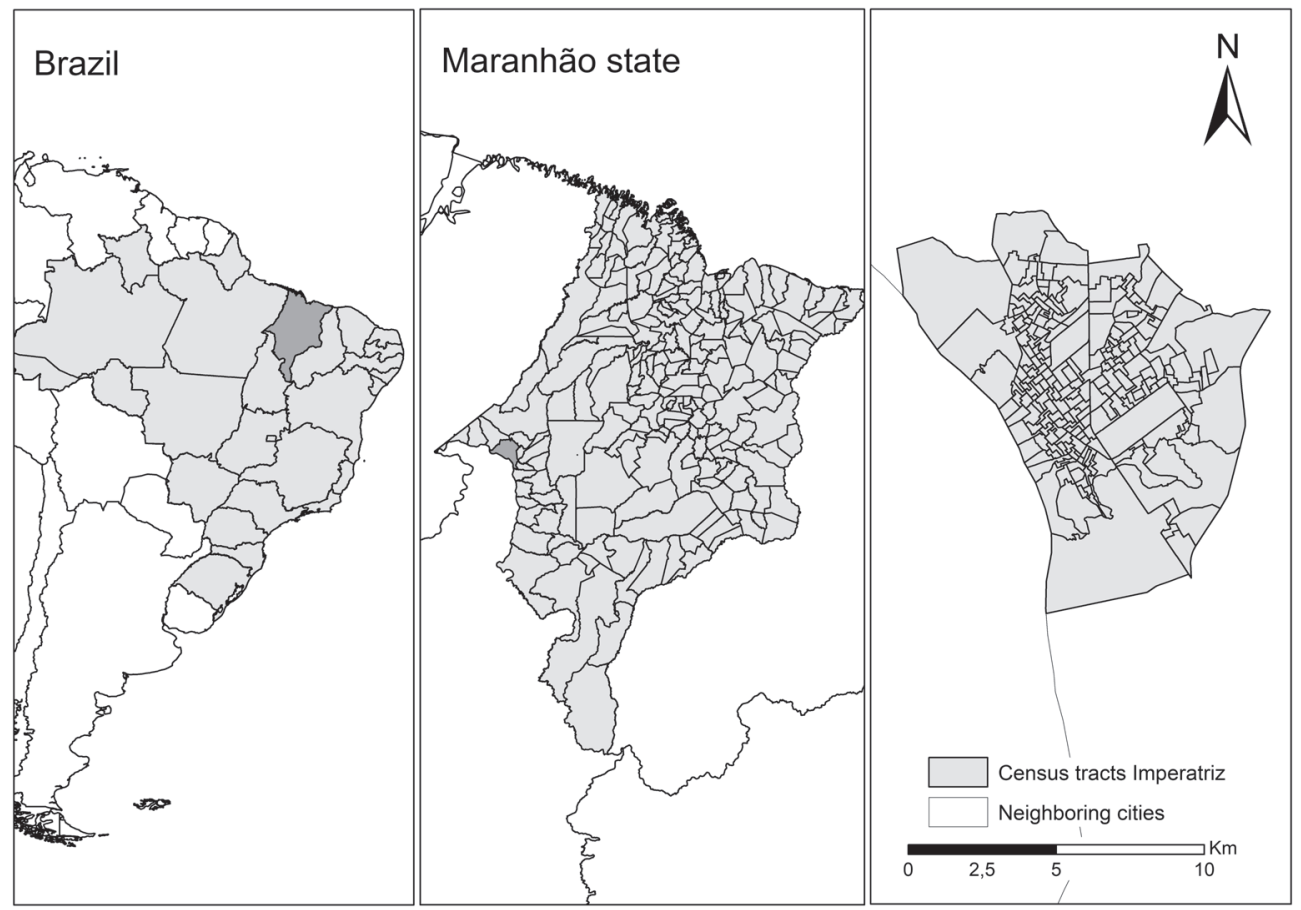

Figure 1. Map of the location of the Imperatriz, Maranhão, Brazil. Source: Brazilian Institute of Geography and Statistics.

The ecological analysis units of the study were the 218 urban census tracts of Imperatriz. The digital map of census tracts was acquired free of charge through the Brazilian Institute of Geography and Statistics (Instituto Brasileiro de Geografia e Estatística - IBGE). The census tract is the smallest territorial unit formed by a continuous area, located in an urban or rural area, with size, number of households and number of residents defined, and is used for the main Brazilian statistical enquires and surveys. ${ }^{30}$

The socioeconomic variables were: number of residents of the household, literacy and household income, collected from the results of the IBGE Demographic Census, aggregated by census tracts. ${ }^{31}$ The selection of variables was based on the leprosy determinants framework of Chapitini and Marshman (2015), ${ }^{32}$ which considers socio-economic/behavioral, location and environmental dimensions. Table 1 presents the variables considered for the construction of the social determinants.

\section{STATISTICAL ANALYSIS}

A descriptive analysis of the clinical and sociodemographic variables of the cases was carried out, with the calculation of absolute frequencies, relative frequencies and rates according to the subgroups of each variable. In the calculation of the rates, for the age and sex variables, the denominator was the municipal population for each subgroup. For the education, operational classification, clinical form and evaluation of the degree of physical disability at diagnosis variables, the denominator was the total population of the municipality. The values were divided by the number of years of study (11 years) and multiplied by 100,000 . For the age 
Table 1. Variables selected from the 2010 Demographic Census (IBGE) for the construction of the social determinants, Imperatriz, Maranhão, Brazil

\begin{tabular}{llc}
\hline Dimension & Variables & Variable code \\
\hline People per household & Proportion of permanent private households with 1 to 3 residents & V01 \\
& Proportion of permanent private households with 4 to 5 residents & V02 \\
& Proportion of permanent private households with 6 to 8 residents & V03 \\
Literacy & Proportion of men without schooling & V04 \\
& Proportion of women without schooling & V05 \\
Household income & $\begin{array}{l}\text { Proportion of households with permanent residents with nominal } \\
\text { monthly income per capita of between 1/2 to 1 minimum wage }\end{array}$ & V06 \\
& $\begin{array}{l}\text { Proportion of households with permanent residents with nominal } \\
\text { monthly income per capita of between 1 to 2 minimum wages }\end{array}$ & V08 \\
& $\begin{array}{l}\text { Proportion of households with permanent residents with nominal } \\
\text { monthly income per capita of between 2 to 3 minimum wages }\end{array}$ &
\end{tabular}

Source: Brazilian Institute of Geography and Statistics.

variable, the measures of position (mean and median) and dispersion (Standard Deviation) were calculated using the R version 3.3.2 software (https://www.r-project.org/). Proportions for the proximal socioeconomic variables of the social determinants were calculated, taking into account the number of households or people with a certain characteristic in each census tract, divided by the total number of households or total number of people in each area, multiplied by 100 .

The cases of leprosy were georeferenced from the geographical coordinates (latitude and longitude) of the residential addresses of each case. The Google Earth $^{\circledR}$ free access software (https://www.google.com/earth/) and the Google Maps ${ }^{\circledR}$ tool (https://www.google.com/maps/) were used to identify geographical coordinates and the $\operatorname{ArcGis}^{\circledR} 10.6$ software (https://www.esri.com/en-us/arcgis/about-arcgis/overview) for georeferencing, with the construction of a file containing the geographical coordinates of each case (represented by points) in SIRGAS 2000 projection. Cases of leprosy were spatially distributed on the digital map of urban census tracts, available from the IBGE website (https://www.ibge.gov.br/geociencias-novoportal/downloads-geociencias.html). ${ }^{30}$ Cases with an address in a rural area ( 84 cases), without an address (316 cases) and/or with an incomplete address (260 cases) were excluded. It was opted to exclude the cases originating from the rural zone due to the impossibility of locating the geographical coordinates in these areas, considering the programs used.

After georeferencing, clusters of leprosy were identified using the scan statistic technique proposed by Kulldorff and Nagarwalla. ${ }^{33}$ This technique is based on the maximum likelihood ratio statistic, based on a Poisson probability distribution (for discrete quantitative variables), adopting the geographical non-overlap of the clusters, circular shaped clusters, and Monte Carlo replication with 999 replications as the parameters.

The scan statistic technique requires a maximum spatial window size defined based on the size of the population or the geographic area of the study. The maximum spatial window size is often defined to be less than or equal to $50 \%$ of the total population at risk. When using a large maximum window size, the maximum likelihood is obtained for a large cluster that contains several smaller clusters, and it is not always clear whether it is better to report one large cluster or several smaller ones. ${ }^{34}$ 
Therefore, to reduce the formation of excessively large clusters with small Relative Risk (RR), Gini Cluster is a methodological option to evaluate the degree of the heterogeneity of the collection of clusters, explaining how well the cluster collection reveals the underlying true cluster patterns. This way, the population at risk indicated by this technique was $8 \%$, which is considered the specification to identify the most important cluster to be reported in the scenario studied. ${ }^{34}$ For this analysis, SaTScan software version 9.6 (https://www.satscan.org/). We defined high-risk areas as those included in clusters with RR greater than 1.

For the construction of the social determinants from the sociodemographic variables, the Principal Component Analysis (PCA) technique was applied using the Statistica ${ }^{\circledR}$ version 10.0 software (http://www.statsoft.com/products/statistica-features). Principal Component Analysis is a statistical approach used to analyze interrelations between a set of variables and explain these variables around their common inherent dimensions, aiming to condense the information contained in the original variables into a smaller set of statistical variables (components) with a minimum loss of information. ${ }^{35}$

In the first stage of the technique, the data were standardized, so that each attribute contributed with the same weight in the calculation of the coefficient of similarity among the objects. After this step, the variables had zero mean and unit variance. Next, the components with total explained variance $>70 \%$ that met the Kaiser criterion, with eigenvalues above 1 , were selected. ${ }^{35}$ Then, the scores for each census tract were calculated by multiplying the eigenvectors by the value of the variables of each census tract.

Following this, binary logistic regression was performed, considering the risk areas of leprosy identified from the spatial scan statistic as the dependent variable, classified as 1 when RR higher than $1(R R>1)$ and 0 when $R R$ is lower than $1(R R<1)$, and the dimensions of the social determinants constructed through the PCA technique as the independent variable. The Odds Ratios (ORs) were calculated along with their respective 95\% Confidence Intervals (95\% CIs) for each PCA covariate. The Hosmer-Lemershow test was applied to estimate the quality of fit of the model and the Receiver Operating Characteristic (ROC) Curve was applied to verify the discriminative power of the model, and its result was classified according to the criterion of Šimundić. ${ }^{36}$ Type I error was set at $5 \%(p<0.05)$. The analyses were performed using the $\mathrm{R}$ version 3.3.2 software.

The study was approved by the Research Ethics Committee of the University of São Paulo at Ribeirão Preto College of Nursing (EERP/USP) under Certificate of Presentation for Ethical Assessment (CAAE) No. 44637215.0.0000.5393. Signing of a consent form was not necessary as secondary data were used and the participants were not identified. The data were analyzed anonymously.

\section{Results}

A total of 3,212 cases of leprosy were reported in Imperatriz during the period investigated. Table 2 shows the descriptive statistics of the cases, where it is possible to observe that highest numbers were observed for age range 30 and 59 years $(1,566 ; 48.76 \%$; rate $=166.46$ per 100,000 inhabitants), males $(1,850 ; 57.60 \%$; rate $=141.06$ per 100,000 inhabitants $)$ and subjects with incomplete elementary education $(1,687 ; 52.52 \%$; rate $=61.96$ per 100,000 inhabitants). Regarding the clinical variables, the main operational classification was multibacillary $(1,966 ; 61.21 \%$; rate $=72.21$ per 100,000 inhabitants $)$, with Grade 1 disability $(515$; $16.03 \%$; rate $=18.91$ per 100,000$)$ and Grade 2 disability $(205 ; 6.38 \%$; rate $=7.52$ per 100,000 inhabitants) at diagnosis. 
Table 2. Main characteristics of the leprosy cases and respective rates per 100,000 inhabitants, Imperatriz, Maranhão, Brazil (2006-2016).

\begin{tabular}{|c|c|c|c|}
\hline Variable & $\begin{array}{l}\text { Absolute frequency } \\
\qquad(n=3,212)\end{array}$ & $\begin{array}{l}\text { Relative frequency } \\
\qquad(\%)\end{array}$ & $\begin{array}{c}\text { Rates }(100,000 \\
\text { inhabitants) }\end{array}$ \\
\hline \multicolumn{4}{|l|}{ Age } \\
\hline Under 15 years & 296 & 9.21 & 40.26 \\
\hline 15 to 29 years & 773 & 24.07 & 93.98 \\
\hline 30 to 59 years & 1,566 & 48.76 & 166.46 \\
\hline$>60$ years & 577 & 17.96 & 257.42 \\
\hline Minimum value & \multicolumn{2}{|c|}{3 years } & - \\
\hline Maximum value & \multicolumn{2}{|c|}{95 years } & - \\
\hline Mean & \multicolumn{2}{|c|}{40.4 years } & - \\
\hline Median & \multicolumn{2}{|c|}{39 years } & - \\
\hline \multicolumn{4}{|l|}{ Gender } \\
\hline Male & 1,850 & 57.60 & 141.06 \\
\hline Female & 1,362 & 42.40 & 96.52 \\
\hline \multicolumn{4}{|l|}{ Education } \\
\hline No schooling & 356 & 11.08 & 13.07 \\
\hline Incomplete elementary education & 1,687 & 52.52 & 61.96 \\
\hline Complete elementary education & 184 & 5.73 & 6.75 \\
\hline Incomplete high school education & 295 & 9.19 & 10.83 \\
\hline Complete high school education & 379 & 11.80 & 13.92 \\
\hline Incomplete higher education & 40 & 1.25 & 1.46 \\
\hline Complete higher education & 88 & 2.74 & 3.23 \\
\hline Declined to answer & 29 & 0.90 & - \\
\hline Not applicable & 46 & 1.43 & - \\
\hline Did not answer & 108 & 3.36 & - \\
\hline \multicolumn{4}{|l|}{ Clinical form } \\
\hline Undetermined & 556 & 17.31 & 20.42 \\
\hline Tuberculoid & 696 & 21.67 & 25.56 \\
\hline Borderline & 1,331 & 41.44 & 48.88 \\
\hline Lepromatous & 609 & 18.96 & 22.36 \\
\hline Not classified & 13 & 0.40 & - \\
\hline Did not answer & 7 & 0.22 & - \\
\hline \multicolumn{4}{|l|}{ Operational classification } \\
\hline Paucibacillary & 1,245 & 38.76 & 45.72 \\
\hline Multibacillary & 1,966 & 61.21 & 72.21 \\
\hline Did not answer & 1 & 0.03 & - \\
\hline \multicolumn{4}{|c|}{$\begin{array}{l}\text { Assessment of the degree of physical } \\
\text { disability at diagnosis }\end{array}$} \\
\hline Grade 0 & 2,087 & 64.97 & 76.65 \\
\hline Grade 1 & 515 & 16.03 & 18.91 \\
\hline Grade 2 & 205 & 6.38 & 7.52 \\
\hline Not evaluated & 381 & 11.87 & - \\
\hline Did not answer & 24 & 0.75 & - \\
\hline
\end{tabular}

Regarding the spatial distribution of the leprosy cases, of the total number of cases $(3,212)$, 84 cases were from the rural area of the municipality and were therefore excluded, according to the study criteria. Of the remaining total $(3,128)$, a further 316 were excluded because the address was blank and 260 because the address was incomplete, leaving 2,552 (81.59\%) for georeferencing. 


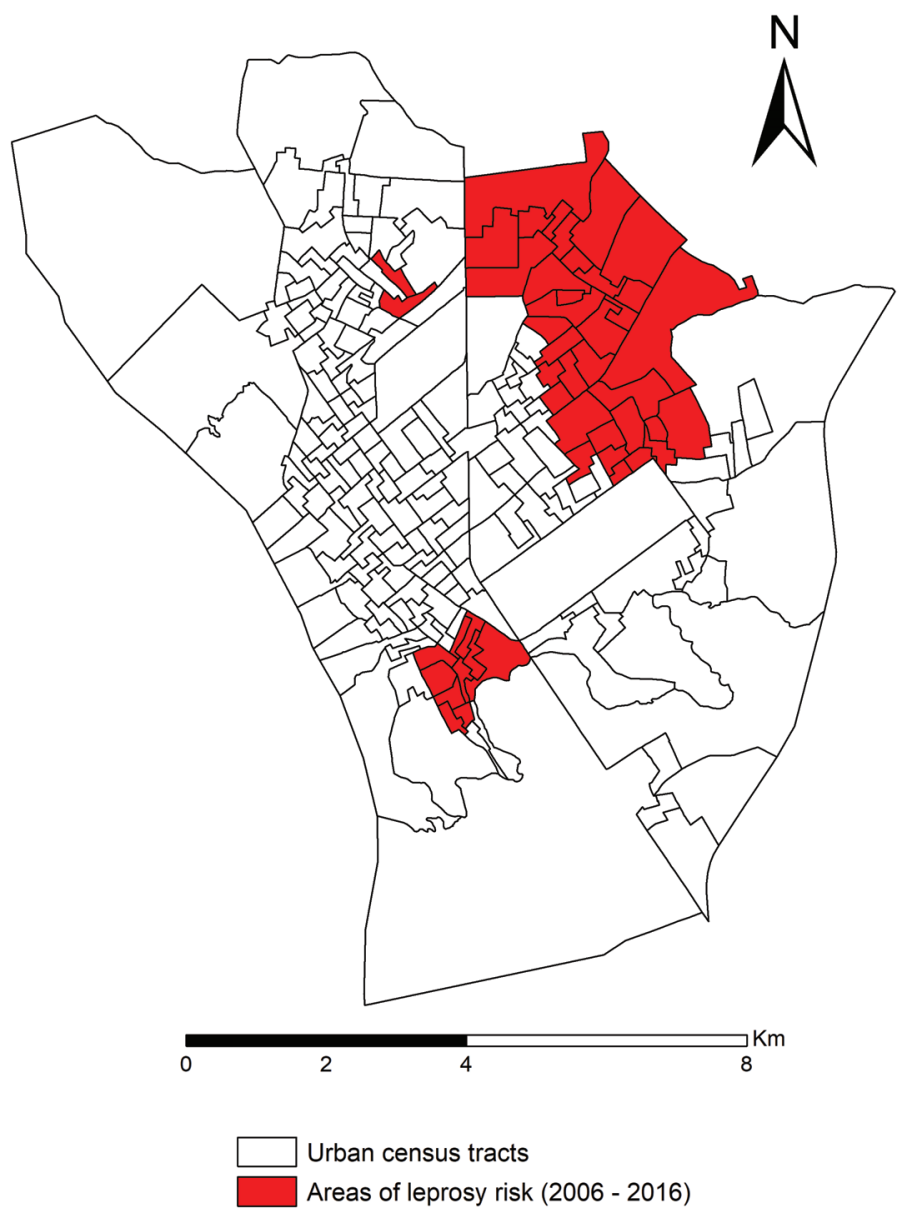

Figure 2. Leprosy high risk areas, Imperatriz, Maranhão, Brazil (2006-2016). Source: Brazilian Institute of Geography and Statistics.

Through the scan statistic it was possible to identify three high-risk clusters statistically significant for leprosy cases (Figure 2). The high-risk areas included the census tracts located in districts 2. Vila Lobão, 3. Bacuri and 4. Santa Rita, located in the northeast and southwest regions of the city of Imperatriz.

Table 3 shows the dimensions of the social determinants identified from the PCA, according to the criteria described in the methods. Dimension 1 presented an eigenvalue of 4.47, with a total explained variance of $55.92 \%$. Dimension 2 presented an eigenvalue of 1.23 , with a total explained variance of $15.45 \%$. Together, the two dimensions explained $71.38 \%$ of the variability of the data.

The variables that contributed positively in dimension 1, in order of importance, were: Proportion of men without schooling, Proportion of women without schooling, Proportion of private permanent households with 6 to 8 residents, Proportion of permanent private households with 4 to 5 residents, and Proportion of permanent private households with nominal monthly income per capita between $1 / 2$ to 1 minimum wage. 
Table 3. Matrix of the original variables and the dimensions of the social determinants, Imperatriz, Maranhão, Brazil

\begin{tabular}{llcc}
\hline Variable code & Variables & \multicolumn{2}{c}{ Social Determinants } \\
\cline { 2 - 3 } & & $\begin{array}{c}\text { Dimension } \\
\text { Dimension } \\
\end{array}$ & 1 \\
\hline V01 & Proportion of permanent private households with 1 to 3 residents & -0.401 & $\mathbf{0 . 1 7 9}$ \\
V02 & Proportion of permanent private households with 4 to 5 residents & $\mathbf{0 . 2 8 1}$ & -0.439 \\
V03 & Proportion of permanent private households with 6 to 8 residents & $\mathbf{0 . 3 5 9}$ & $\mathbf{0 . 2 5 3}$ \\
V04 & Proportion of Men without schooling & $\mathbf{0 . 3 9 3}$ & $\mathbf{0 . 2 9 5}$ \\
V05 & Proportion of women without schooling & $\mathbf{0 . 3 7 8}$ & $\mathbf{0 . 2 0 9}$ \\
V06 & Proportion of permanent private households with nominal & $\mathbf{0 . 0 7 5}$ & -0.725 \\
& monthly income per capita of between 1/2 to 1 minimum wage & -0.409 & -0.108 \\
V07 & Proportion of permanent private households with nominal & \\
& monthly income per capita of between 1 to 2 minimum wages & -0.398 & $\mathbf{0 . 2 0 1}$ \\
V08 & Proportion permanent private households with nominal monthly & & \\
& income per capita of between 2 to 3 minimum wages &
\end{tabular}

Table 4. Predictive analysis of the social determinants associated with the areas at risk of leprosy, Imperatriz, Maranhão, Brazil (2006-2016)

\begin{tabular}{lccccccc}
\hline & Social Determinants & Coefficient & Odds Ratio & $(95 \%$ CI $)$ & $p$ & ROC \\
\hline Model 1 & Dimension 1 & 0.23 & 1.25 & $1.07-1.49$ & 0.006 & 0.65 \\
Model 2 & Dimension 2 & -0.08 & 0.97 & $0.72-1.30$ & 0.876 & - \\
\hline
\end{tabular}

In dimension 2, the variables that contributed positively in order of importance were: Proportion of men without schooling, Proportion of private permanent households with 6 to 8 residents, Proportion of women without schooling, Proportion of permanent private households with nominal monthly income per capita between 2 to 3 minimum wages, and Proportion of permanent private households with 1 to 3 residents.

The dimensions of the social determinants were tested for the areas at high-risk for leprosy, observing the results of the statistics in Table 4. The final model showed that dimension 1 (greater number of residents, education deficits and low income) was associated with highrisk areas $(\mathrm{OR}=1.25 ; 95 \% \mathrm{CI}=1.07-1.49 ; p=0.006)$.

The area under the ROC curve value for dimension 1 showed that its discriminatory capacity for the high-risk areas of leprosy was $65 \%$, the discriminatory power of the model was classified as sufficient. ${ }^{36}$ The value of Nagelkerke's $\mathrm{R}^{2}$ coefficient was 0.05 , the model can explain about $5 \%$ of the variations registered in the dependent variable. The Hosmer-Lemeshow test showed a value of $p=0.529$, showing a good model fitness. The diagnosis of the logistic regression model indicated its adequacy and the non-violation of assumptions.

\section{Discussion}

The results of the study indicate that areas at high-risk for leprosy are associated with certain social determinants in a hyperendemic city of northeastern Brazil. The ROC demonstrated the sufficient prediction capacity of the model to explain the high-risk areas in Imperatriz. ${ }^{36}$ The findings also show an overall detection rate of 108.76 cases per 100,000 inhabitants, confirming the hyperendemic profile according to the parameters of the Brazilian Ministry of Health. ${ }^{9}$ The municipality has shown rapid demographic growth, being the second economic center of 
the state of Maranhão, receiving a large number of migrants from northern and northeastern Brazilian states due to its influence in the local economy, which may be causing an increase of the bacillus circulating in the studied region. ${ }^{37,38}$

The age group most affected in the period investigated was that of 30 to 59 years, an age group that includes the economically active Brazilian population. The involvement of people in this age group can hinder the development of work activities, which can lead to its interruption, early retirements and a decrease in the quality of life of workers. ${ }^{17,39,40}$

There was a high rate of cases in males, corroborating the literature, ${ }^{16,17,24,41}$ with the higher incidence in this sex possibly being related to longer exposure to the bacillus and less care for the health, leading to late diagnosis and increased risk for the development of physical disabilities. ${ }^{42}$ Regarding the educational level, the majority of cases had incomplete primary education, corresponding to less than five years of schooling (incidence of 61.96 cases per 100,000 inhabitants), with low educational levels having been described in the literature as a risk factor for leprosy. ${ }^{16,32}$ According to some authors, people with low levels of education have difficulty understanding the pathophysiological mechanisms and clinical manifestations of the disease and also tend to present greater difficulty in seeking health services and access to them. ${ }^{12,16,23,43}$

Regarding the clinical profile of the disease, there were high rates among the multibacillary patients with a borderline clinical form (incidence of 48.88 cases per 100,000 inhabitants). High rates of Grades 1 and 2 disability at diagnosis were also observed, being 18.91 and 7.52 cases per 100,000 inhabitants, respectively, which may have occurred as a result of the delayed diagnosis. In the literature, the predominance of the borderline and lepromatous clinical forms and degrees of physical disability in the general distribution of cases suggests the occurrence of active transmission of the disease and late diagnosis, since, given the long latency period of Mycobacterium leprae, the immune system of the individuals is already compromised, with the development of more severe forms. ${ }^{44,45}$

The study suggests that the areas at high-risk for leprosy are associated with the social determinants of low income, low schooling and high number of residents per household. The areas of leprosy high risk include census tracts located in districts 2. Vila Lobão, 3. Bacuri and 4. Santa Rita, located in the northeast and southwest of the municipality. A common characteristic of these three districts is that they are peripheral regions, far from the urban center of the city, and due to the rapid occupation of these regions, some pockets of poverty have been formed, with a consequent increase in situations of social inequality. ${ }^{38}$

A study carried out in the city, evaluating the incidence of leprosy in children under 15 years of age, found that the highest occurrence of cases was located in health district 4. Santa Rita, in the northeast of the city. This district is characterized by a high population density, low socioeconomic level and deficits in basic sanitation, ${ }^{28}$ which corroborates the present investigation, in which the areas of risk included this district.

In Brazil, previous analyses identify 10 clusters with the highest-transmission of leprosy, of which the highest relative risk was located in the municipalities from north and northeast of the country, including the states of Maranhão, Pará, Tocantins and Piaui. ${ }^{18}$ According to the authors, social determinants that include high number of residents per household, low income may be associated with the high transmission of leprosy, aspects identified in the present study.

Penna et al., ${ }^{8}$ in 2009, analyzed the spatial distribution of leprosy in Brazil and verified an increase in detection rates in some areas, with the formation of clusters. According to the authors, this can be explained by two causes. First, the improvement of access to health services may be favoring the increase of this detection. Second, local context factors may be 
contributing to the delimitation, maintenance and circulation of the bacillus in these clusters, due to the occupation of urban space, housing characteristics, family aggregation habits, and increased flow of people (migration) motivated by economic conditions.

The literature highlights that municipalities with high rates of people with low levels of education, greater population size, higher proportions of households with inadequate sanitation, higher rates of urbanization, higher average number of people per household and per room, and higher income inequality present higher rates of leprosy. ${ }^{21,23,46}$

Social determinants that include lack of education and low income were favorable to the high incidence of the disease in the municipality of Imperatriz. The degree of economic inequality was the variable most associated with the incidence of leprosy in Imperatriz, demonstrating that the more heterogeneous the income distribution of a municipality, the greater the probability of this disease being an important public health problem. ${ }^{21,47}$

Another variable that is associated with the increased risk of transmission of leprosy is related to the interregional migratory flow present in Brazil. The state of Maranhão is one of the states of the northeast with greater emigration and immigration, especially with the neighboring states, which may explain the maintenance of high detection rates of leprosy. ${ }^{37}$ In addition, Maranhão is one of the states with the largest rural exodus, where rural migration to urban centers, such as the municipality of Imperatriz, is a common solution to reduce poverty. This process of urbanization, however, is accompanied by precarious housing and living conditions, with the formation of pockets of poverty, which maintains the circulation of the bacillus. ${ }^{37}$ Thus, explanations for the persistence of leprosy in clusters described in the study and by other authors may be a consequence of the persistence of pockets of poverty and the precarious living conditions of these populations. Accordingly, coping strategies should include measures of income distribution, social inclusion and improvements in general living conditions, in particular, the implementation of social protection measures. ${ }^{46}$

One measure to reduce social inequalities adopted in Brazil concerns the Brazilian conditional monetary transfer program, called the Programa Bolsa Família (PBF). The PBF is intended for extremely poor families and poor families, with children or adolescents up to the age of 17 or for pregnant or breast feeding women. ${ }^{48-50}$ A study that verified the association between leprosy detection rate and PBF coverage evidenced an increasing tendency in the mean coverage of the PBF and a reduction in the detection rates of leprosy in children under 15 years of age in municipalities with high risk of transmission of the disease, revealing a protective effect of this program. ${ }^{51}$ Although the present study did not measure PBF coverage, it should be emphasized that income transfer and social protection policies in general are strategic and important for reducing social inequalities, and such actions should be valued, especially in the risk areas identified in the study. Based on the present study and the literature evidence found, the main measures for the elimination of leprosy as a public health problem in Brazil should be directed toward reducing social inequalities (in which Brazil is one of the world leaders) and strengthening health systems and services in relation to early diagnosis, prevention of physical disabilities, active case search, intradomiciliary contact evaluation and stigma reduction.

Among the limitations of the study, the use of secondary information sources, with the presence of unavailable and incomplete data, should be highlighted. Another limitation was the difficulty in selecting the variables of the IBGE related to social determinants, due to the lack of information from some census tracts.

In conclusion, the study provides evidence that the areas at high-risk for leprosy are associated with social determinants of low household per capita income, low educational levels and high numbers of residents per household. Considering the results of the ROC curve, 
which the discriminatory capacity of the final model was classified as sufficient, it is worth mentioning that there are other determinant factors for the occurrence of the leprosy that need different methodological approaches to be identified. However, the verification of the association of the disease with social determinants, as showed in this study, is useful for the planning of actions addressed to the reduction in these inequalities, and may contribute to the reduction of leprosy transmission in municipalities with high endemicity of leprosy.

\section{Acknowledgements}

The authors would like to thank the Health Surveillance Service of the Imperatriz Regional Health Management Unit, of the state government of Maranhão for making the data available.

\section{Funding information}

This study was financed in part by the Coordenação de Aperfeiçoamento de Pessoal de Nível Superior - Brasil (CAPES) - Finance Code 001.

\section{Contributions of each author}

ACV Ramos, RA Arcêncio was involved in Conceptualization, Formal analysis, Investigation, Methodology, Writing - original draft, Writing - review \& editing.

M Santos Neto, FM Pieri was involved in Investigation, Writing - original draft, Writing review \& editing.

M Yamamura, LH Arroyo, IS Assis, MAM Arcoverde was involved in Formal analysis, Methodology.

JD Alves, LS Alves, TZ Berra, JF Martoreli Júnior was involved in Writing - original draft, Writing - review \& editing.

\section{References}

1 World Health Organization (WHO). Guidelines for the Diagnosis, Treatment and Prevention of Leprosy. New Delhi: World Health Organization, Regional Office for South-East Asia; 2017. Available from: https://www.who.int/lep/resources/9789290226383/en/.

2 Barbosa CC, Bonfim CVD, de Brito CMG, Ferreira AT, Gregório VRDN, de Oliveira ALS et al. Spatial analysis of reported new cases and local risk of leprosy in hyper-endemic situation in Northeastern Brazil. Trop Med Int Heal, 2018; 23(7): 748-757. Available from: https://doi.org/10.1111/tmi.13067.

3 Mitjà O, Marks M, Bertran L, Kollie K, Argaw D, Fahal AH et al. Integrated control and management of neglected tropical skin diseases. PLoS Negl Trop Dis, 2017; 11(1): e0005136. Available from: https://doi.org/10.1371/journal.pntd.0005136.

4 Molyneux DH. The London declaration on neglected tropical diseases: 5 years on. Trans R Soc Trop Med Hyg, 2016; 110(11): 623-625. Available from: https://doi.org/10.1093/trstmh/trw082.

5 World Health Organization (WHO). Global Leprosy Strategy 2016-2020: Accelerating towards a leprosy-free world. WHOSEARO/Department of Control of Neglected Tropical Diseases, New Delhi; 2016. Available from: https://www.who.int/lep/resources/9789290225096/en/.

6 World Health Organization (WHO). WHO: Global leprosy update, 2017: reducing the disease burden due to leprosy. Weekly Epidemiological Record, 2018; 93(35): 445-456. Available from: https://www.who.int/ wer/2018/wer9335/en/.

7 Brasil. Ministério da Saúde. Departamento de Informática do SUS (DATASUS). Indicadores epidemiológicos e operacionais de hanseníase, por ano diagnóstico - Brasil - (2000-2017). 2019. Available from: http://tabnet.datasus.gov.br/cgi/dhdat.exe?hanseniase/hantfma17.def.

8 Penna MLF, de Oliveira MLVDR, Penna GO. The epidemiological behaviour of leprosy in Brazil. Lepr Rev, 2009; 80(3): 332-344. Available from: https://www.lepra.org.uk/platforms/lepra/files/lr/Sept09/1473.pdf. 
9 Brasil. Ministério da Saúde. Secretaria de Vigilância em Saúde. Departamento de Vigilância das Doenças Transmissíveis. Diretrizes para vigilância, atenção e eliminação da hanseníase como problema de saúde pública. 1st ed. Brasília; 2016. Available from: http://www.saude.pr.gov.br/arquivos/File/ Manual_de_Diretrizes_Eliminacao_Hanseniase.pdf.

10 Bakker MI, Hatta M, Kwenang A, Van Mosseveld P, Faber WR, Klatser PR et al. Risk factors for developing leprosy-a population-based cohort study in Indonesia. Lepr Rev, 2006; 77(1): 48-61. Available from: https://www.lepra.org.uk/platforms/lepra/files/lr/Mar06/Lep048-061.pdf.

11 Bakker MI, Hatta M, Kwenang A, Faber WR, van Beers SM, Klatser PR et al. Population survey to determine risk factors for Mycobacterium leprae transmission and infection. Int J Epidemiol, 2004; 33(6): 1329-1336. Available from: https://doi.org/10.1093/ije/dyh266.

12 Grantz KH, Chabaari W, Samuel RK, Gershom B, Blum L, Worden L et al. Spatial distribution of leprosy in India: An ecological study. Infect Dis Poverty, 2018; 7(20): 1-9. Available from: http://dx.doi.org/ 10.1186/s40249-018-0402-y.

13 Daniel OJ, Adejumo OA, Oritogun KS, Omosebi O, Kuye J, Akang G. Spatial distribution of leprosy in Nigeria. Lepr Rev, 2016; 87: 476-485. Available from: https://www.ncbi.nlm.nih.gov/pubmed/30226352.

14 Daniel OJ, Adejumo OA, Oritogun KS, Omosebi O, Kuye J, Onyemaechi S et al. Leprosy disease burden, active transmission and late presentation at the lowest administrative level in Nigeria: A spatial approach. Lepr Rev, 2017; 88: 343-353. Available from: https://www.lepra.org.uk/platforms/lepra/files/lr/Sept17/Lep343-353.pdf.

15 Fischer EAJ, Pahan D, Chowdhury SK, Richardus JH. The spatial distribution of leprosy cases during 15 years of a leprosy control program in Bangladesh: An observational study. BMC Infect Dis, 2008; 8(126): 1-10. Available from: https://doi.org/10.1186/1471-2334-8-126.

16 Asis IS, Arcoverde MAM, Ramos ACV, Alves LS, Berra TZ, Arroyo LH et al. Social determinants, their relationship with leprosy risk and temporal trends in a tri-border region in Latin America. PLoS Negl Trop Dis, 2018; 12(4): e0006407. Available from: https://doi.org/10.1371/journal.pntd.0006407.

17 Ramos ACV, Yamamura M, Arroyo LH, Popolin MP, Chiaravalloti Neto F, Palha PF et al. Spatial clustering and local risk of leprosy in São Paulo, Brazil. PLoS Negl Trop Dis, 2017; 11(2): e0005381. Available from: https://doi.org/10.1371/journal.pntd.0005381.

18 Penna MLF, Oliveira MLW-R, Penna G. Spatial distribution of leprosy in the amazon region of Brazil. Emerg Infect Dis, 2009; 15(4): 650-652. Available from: https://doi.org/10.3201/eid1504.081378.

19 Rodrigues-Júnior AL, do O VT, Motti VG. Spatial and temporal study of leprosy in the state of São Paulo (Southeastern Brazil), 2004-2006. Rev saúde pública, 2008; 42(6): 1012-1020. Available from: https://doi.org/10.1590/S0034-89102008000600006.

20 Alencar CH, Ramos AN, dos Santos ES, Richter J, Heukelbach J. Clusters of leprosy transmission and of late diagnosis in a highly endemic area in Brazil: focus on different spatial analysis approaches. Trop Med Int Heal, 2012; 17(4): 518-525. Available from: https://doi.org/10.1111/j.1365-3156.2011.02945.x.

21 Kerr-Pontes LRS, Montenegro ACD, Barreto ML, Werneck GL, Feldmeier H. Inequality and leprosy in Northeast Brazil: An ecological study. Int J Epidemiol, 2004; 33(2): 262-269. Available from: https://doi.org/10.1093/ije/dyh002.

22 Cabral-Miranda W, Chiaravalloti Neto F, Barrozo LV. Socio-economic and environmental effects influencing the development of leprosy in Bahia, north-eastern Brazil. Trop Med Int Heal, 2014; 19(12): 1504-1514. Available from: https://doi.org/10.1111/tmi.12389.

23 Freitas LRS, Duarte EC, Garcia LP. Leprosy in Brazil and its association with characteristics of municipalities: ecological study, 2009-2011. Trop Med Int Health, 2014; 19(10): 1216-1225. Available from: https://doi.org/10.1111/tmi.12362.

24 Marciano LHSC, de Belone AFF, Rosa PS, Coelho NMB, Ghidella CC, Miranda WC et al. Epidemiological and geographical characterization of leprosy in a Brazilian hyperendemic municipality. Cad Saude Publica, 2018; 34(8): e00197216. Available from: https://doi.org/10.1590/0102-311x00197216.

25 Barreto JG, Bisanzio D, Guimarães LS, Spencer JS, Vazquez-Prokopec GM, Kitron U et al. Spatial analysis spotlighting early childhood leprosy transmission in a hyperendemic municipality of the brazilian amazon region. PLoS Negl Trop Dis, 2014; 8(2): e2665. Available from: https://doi.org/10.1371/journal.pntd.0002665.

26 Morgenstern H. Ecologic studies in principles, and methods. Annu Rev Public Heal, 1995; 16: 61-81. Available from: https://doi.org/10.1146/annurev.pu.16.050195.000425.

27 Instituto Brasileiro de Geografia e Estatística (IBGE). Panorama Municipal de Imperatriz/MA. 2019. Available from: https://cidades.ibge.gov.br/brasil/ma/imperatriz/panorama.

28 de Gordon ASA, Gomes JMS, de Costa ACPJ, de Serra MAAO, Xavier MB. Incidência de hanseníase em menores de 15 anos acompanhados no município de Imperatriz, Maranhão, Entre 2004 e 2010. Arq Ciênc Saúde UNIPAR, 2017; 21(1): 19-24. Available from: https://doi.org/10.25110/arqsaude.v21i1.2017.6072. 
29 Brasil. Ministério da Saúde. Secretaria de Vigilância em Saúde. Departamento de Vigilância Epidemiológica. Sistema de Informação de Agravos de Notificação - Sinan: normas e rotinas. 2nd ed. Brasília; 2007. Available from: http://bvsms.saude.gov.br/bvs/publicacoes/sistema_informacao_agravos_notificacao_sinan.pdf.

30 Instituto Brasileiro de Geografia e Estatística (IBGE). Malha de Setores Censitários 2010. 2011. Available from: https://downloads.ibge.gov.br/downloads_geociencias.htm.

31 Instituto Brasileiro de Geografia e Estatística (IBGE). Base de informações do Censo Demográfico 2010: Resultados do Universo por setor censitário - Documentação do Arquivo. Rio de Janeiro; 2011. Available from: https://www.ibge.gov.br/estatisticas/downloads-estatisticas.html.

32 Chaptini C, Marshman G. Leprosy: A review on elimination, reducing the disease burden, and future research. Lepr Rev, 2015; 86: 307-315. Available from: https://www.lepra.org.uk/platforms/lepra/files/lr/Dec15/150030.pdf.

33 Kulldorff M, Nagarwalla N. Spatial disease clusters: detection and inference. Stat Med, 1995; 14(8): 799-810. Available from: https://doi.org/10.1002/sim.4780140809.

34 Han J, Zhu L, Kulldorf M, Hostovich S, Stinchomb DG, Tatalovich Z et al. Using Gini coefficient to determining optimal cluster reporting sizes for spatial scan statistics. Int J Health Geogr. BioMed Central, 2016; 15(27): 1-11. Available from: https://doi.org/10.1186/s12942-016-0056-6.

35 Hair JF, Anderson RE, Tatham RL, Black WC, Babin BJ. Multivariate Data Analysis. 6th ed., Pearson; 2005.

36 Šimundić A-M. Measures of diagnostic accuracy: Basic definitions. Ejifcc, 2009; 19(4): 203-211. Available from: http://www.pubmedcentral.nih.gov/articlerender.fcgi?artid=PMC4975285.

37 Murto C, Chammartin F, Schwarz K, da Costa LMM, Kaplan C, Heukelbach J. Patterns of migration and risks associated with leprosy among migrants in Maranhão, Brazil. PLoS Negl Trop Dis, 2013; 7(9): e2422. Available from: https://doi.org/10.1371/journal.pntd.0002422.

38 Oliveira AN. Ambient costs socioeconômicos and of the impacts of the urbanization of Imperatriz in the urban sources: a study of case in the micro-bacia of Stream Bacuri. Pará. M.Sc. Thesis, Federal University of Para. 2005. Available from: http://repositorio.ufpa.br/jspui/handle/2011/1958.

39 Monteiro LD, de Alencar CHM, Barbosa JC, Braga KP, de Castro MD, Heukelbach J. Incapacidades físicas em pessoas acometidas pela hanseníase no período pós-alta da poliquimioterapia em um município no Norte do Brasil. Cad Saude Publica, 2013; 29(5): 909-920. Available from: https://doi.org/10.1590/S0102311 X2013000500009.

40 Nicchio MVC, Araujo S, Martins LC, Pinheiro AV, Pereira DC, Borges A et al. Spatial and temporal epidemiology of Mycobacterium leprae infection among leprosy patients and household contacts of an endemic region in Southeast Brazil. Acta Trop, 2016; 163: 38-45. Available from: https://doi.org/10.1016/ j.actatropica.2016.07.019.

41 Melão S, Blanco LFDO, Mounzer N, Veronezi CCD, de Simões PWTA. Perfil epidemiológico dos pacientes com hanseníase no extremo sul de Santa Catarina, no período de 2001 a 2007. Rev Soc Bras Med Trop, 2011; 44(1): 79-84. Available from: https://doi.org/10.1590/S0037-86822011000100018.

42 Nobre ML, Illarramendi X, Dupnik KM, de Hacker MA, da Nery JAC, Jerônimo SMB et al. Multibacillary leprosy by population groups in Brazil: Lessons from an observational study. PLoS Negl Trop Dis, 2017; 11(2): e0005364. Available from: https://doi.org/10.1371/journal.pntd.0005364.

43 Santos AS, Castro DS, Falqueto A. Risk factors for Leprosy transmission. Rev Bras Enferm, 2008; 61(spe): 738-743. Available from: https://doi.org/10.1590/S0034-71672008000700014.

44 Cury MRCO, Paschoal VDA, Nardi SMT, Chierotti AP, Rodrigues Júnior A, Chiaravalloti-Neto F. Spatial analysis of leprosy incidence and associated socioeconomic factors. Rev Saude Publica, 2012; 46(1): 110-118. Available from: https://doi.org/10.1590/S0034-89102011005000086.

45 Eichelmann K, González SEG, Salas-Alanis JC, Ocampo-Candiani J. Lepra: puesta al día. Definición, patogénesis, clasificación, diagnóstico y tratamiento. Actas Dermosifiliogr, 2013; 104(7): 554-563. Available from: https://doi.org/10.1016/j.ad.2012.03.003.

46 de Freitas LRS, Duarte EC, Garcia LP. Analysis of the epidemiological situation of leprosy in an endemic area in Brazil: spatial distribution in the periods 2001-2003 and 2010-2012. Rev Bras Epidemiol, 2017; 20(4): 702713. Available from: https://doi.org/10.1590/1980-5497201700040012.

47 Gracie R, de Peixoto JNB, dos Soares FBR, de Hacker MAV-B. Análise da distribuição geográfica dos casos de hanseníase. Rio de Janeiro, 2001 a 2012. Cien Saude Colet, 2017; 22(5): 1695-1704. Available from: https://doi.org/10.1590/1413-81232017225.24422015.

48 Nery JS, Pereira SM, Rasella D, Penna MLF, Aquino R, Rodrigues LC et al. Effect of the brazilian conditional cash transfer and primary health care programs on the new case detection rate of leprosy. PLoS Negl Trop Dis, 2014; 8(11): e3357. Available from: https://doi.org/10.1371/journal.pntd.0003357.

49 Rasella D, Aquino R, Santos CAT, Paes-Sousa R, Barreto ML. Effect of a conditional cash transfer programme on childhood mortality: A nationwide analysis of Brazilian municipalities. Lancet, 2013; 382(9886): 57-64. Available from: https://doi.org/10.1016/S0140-6736(13)60715-1. 
50 Campello T, Neri MC. Programa Bolsa Família: uma década de inclusão e cidadania. Brasília: Ipea; 2013. 494 p. Available from: http://www.ipea.gov.br/portal/images/stories/PDFs/livros/livros/livro_bolsafamilia_10anos.pdf.

51 de Andrade KVF, Nery JS, Penna MLF, Penna GO, Barreto ML, Pereira SM. Effect of Brazil's conditional cash transfer programme on the new case detection rate of leprosy in children under 15 years old. Lepr Rev, 2018; 89: 13-24. Available from: https://www.lepra.org.uk/platforms/lepra/files/lr/Mar18/Lep013-024.pdf. 